\title{
AN EVALUATIVE FRAMEWORK FOR RESEARCH ON THE PERFORMANCE EFFECTS OF INFORMATION TECHNOLOGY INVESTMENT
}

\author{
by \\ Robert J. Kauffman \\ Leonard N. Stern School of Business \\ Information Systems Department \\ New York University \\ 90 Trinity Place \\ New York, NY 10006 \\ and \\ Peter Weill \\ Graduate School of Management \\ University of Melbourne \\ 200 Leicester Street \\ Carlton 3053 \\ Melbourne, Australia
}

\begin{abstract}
July 1989
Center for Research on Information Systems

Information Systems Department

Leonard N. Stern School of Business

New York University
\end{abstract}

\section{Working Paper Series}

CRIS \#214

STERN \#89-83

Copyright (C) 1989 Robert J. Kauffman and Peter Weill

Forthcoming in Proceedings of the Tenth International Conference on Information Systems, Boston, Massachusetts, December 1989. 


\title{
OF INFORMATION TECHNOLOGY INVESTMENT
}

\author{
Robert J. Kauffman \\ New York University \\ Peter Weill \\ University of Melbourne
}

\begin{abstract}
Firms today invest enormous resources in information technology with the hope of gaining significant returns which will impact their performance. A growing body of research into the firm performance effects of IT investment has emerged and is sometimes referred to as IT business value research. The problem researchers face is identifying robust methods to gain insight into how IT business value is created. This paper reports on the state of IT business value research by reviewing thirteen empirical studies. It also proposes a new evaluative framework to identify strengths and weaknesses in this research. The paper concludes with a series of recommendations to improve the quality of future IT business value research.
\end{abstract}




\section{Introduction}

Senior managers responsible for determining the level of a corporation's resources to invest in information technology (IT) are struggling with the difficult challenge of evaluating the value of their IT investments. The problem is a simple one: the best IT investments are those which help to maximize the value of the firm. But IT creates impacts at several levels in the organization, and some only indirectly contribute to profitability. The problem is so complex in practice that in a recent Index Systems poll of 240 senior information systems (IS) managers, $90 \%$ said they did not know how to measure the leverage IT was creating. Despite these concerns, still more than one-half believed that their IT investments were enhancing firm performance (Computerworld 1988a; Connelly 1988). Apparently, managers are faced with investing in IT based on a "gut feeling" that value will ensue, without having good measures to determine the performance effects.

Two years ago in a paper which appeared in these proceedings, Bakos (1987) appealed to other researchers in the IS field to develop a tradition of common technique, broadly agreed upon and tested value measures, and models which capture the direct impacts of IT, wherever they occur in the firm. It is our observation in 1989 that we are beginning to build up "critical mass" in this area of IS research. If the major questions are not yet answered, at least they appear to be on the table and under close scrutiny. For example, the American Banker, the daily newspaper of the U.S. banking community, published a special issue last year which attempted to evaluate how return and bottom line performance were related to technology investments (Zimmerman 1988). Computerworld also recently published a special survey on the effectiveness of IT investments, including a description of the method they used to distinguish among leading edge firms and those perceived as having substandard performance (Computerworld 1988b). Also, within the last year and a half, the International Center for Information Technology sponsored a seminar series on Measuring Business Value of Information Technologies and published a book with the same name (Berger, Kobelius and Sutherland 1988).

The problem that we face as researchers in IT value analysis is identifying robust methods that give reliable results in a variety of settings. IT business value research is concerned with measuring the effects of investment in IT on aspects of firm performance. In this paper we report on thirteen empirical studies of IT business value and observe that convergence is occurring particularly in the area of appropriate methods. Our primary goal here is to focus on the question of methodological advance, both as a means to help managers get better results and to suggest how additional research can build on the critical mass. Having recently completed separate dissertation research projects on the business value of IT in different settings (financial services (Kauffman 1988) and manufacturing (Weill 1988)), we have experienced first hand the difficulties of getting persuasive results.

The paper is organized as follows. Section 2 briefly describes the IT business value studies that we use as the basis of our critique. The studies we have chosen constitute a representative body of work, and a wide range of methods, variables and models were employed. Section 3 extends our critique in terms of the appropriateness of the methods used to get results. To structure this critique we have identified an evaluative framework including three general classes of considerations important to the success of any IT business value study. We proceed to analyze IT business value research using this framework, and both the strengths and weaknesses of the studies are identified. Section 4 concludes the paper with a series of recommendations for future research. 


\section{Overview of Previous Work Critiqued}

Bakos (Bakos 1987) identified five levels at which IT business value analyses can be carried out:

- the economy as a whole;

- the industry within an economy;

- the firm within an industry;

- a work group or division within a firm;

- the individual or information system.

The studies we consider span all of Bakos' five levels. As a basis for deciding which studies to include, we carefully examined the descriptions the authors provided about the data sets used in their studies. Quality work in this area is not feasible unless care has been taken in assembling a data set which measures relevant aspects of performance and IT investment, and is large enough to provide a reasonable level of statistical power. The studies shown in Table 1 below more than meet each of these criteria.

One important commonality among the studies is strikingly apparent: many found little persuasive evidence that IT investments created strong leverage on the value of the firm. Lucas (1975), for example, found that information system usage was not a very good predictor of performance among the more than 200 California bank branches he studied. Cron and Sobol (1983) identified that surgical warehousing companies making extensive use of IT were either very strong or very weak financial performers. Working at the level of the macroeconomy, Jonscher (1983) found that computer investment did little to speed up white collar productivity between the 1950s and the 1980s; in fact, he observed that "information handling" work actually lagged production work in efficiency gains. Turner (1985) also found little evidence to suggest that mutual savings banks which made relatively larger investments in IT compared to industry competitors performed better. More recently, Roach (1987), an economist with Morgan Stanley, was unable to detect any significant baseline changes in service sector productivity, despite the large investments made since the 1960s. Banker and Kauffman (1988a) also found little evidence of value from investments in automated teller machine (ATM) network technology. Instead their empirical results showed that ATM deployment helped to protect a bank branch's deposit base rather than extend it greatly; only a very restricted set of competitive conditions were found to be conducive to the creation of this kind of business value via ATM deployment. Finally, Loveman (1988) presented results which showed IT created little value in terms of manufacturing sector output productivity, despite his use of well-accepted econometric methods and a solid data set.

Next, consider the studies which presented more favorable conclusions about the role of IT investments in leveraging better performance. Harris and Katz (1988) found that insurance firm profitability was related to the level of IT investments. Results presented by Bender (1986) suggested the "optimal" level of IT investment expense as a percentage of total expenditures within the insurance industry was between $20 \%$ to $25 \%$. The PIMS study (1984) supplemented this view by identifying IT expense as a component of overall "management costs" for the many firms in a large proprietary database. ${ }^{1}$

\footnotetext{
${ }^{1}$ The database is well-known among IS practitioners and researchers: a firm provides answers to a large questionnaire about its investments and performance, and receives analyses which describe its "fingerprint" relative to those of anonymous industry competitors.
} 


\begin{tabular}{|c|c|c|c|}
\hline AUTHOR & INDUSTRY & DATA SOURCE & SUMMARY OF MAJOR RESULTS \\
\hline $\begin{array}{l}\text { Lucas } \\
\qquad(1975)\end{array}$ & Banking & $\begin{array}{l}200+\text { branches } \\
\text { in California }\end{array}$ & $\begin{array}{l}\text { Usage, not investment level, } \\
\text { the key performance indicator }\end{array}$ \\
\hline (1983) & Wholesalers & $\begin{array}{l}138 \text { firms in } \\
\text { Surgical Trade } \\
\text { Assn. survey }\end{array}$ & $\begin{array}{l}\text { Detected bimodal distribution } \\
\text { of performance for firms with } \\
\text { large IT investments }\end{array}$ \\
\hline $\begin{array}{l}\text { Jonscher } \\
\text { (1983) }\end{array}$ & $\begin{array}{l}\text { Economy as } \\
\text { a whole }\end{array}$ & $\begin{array}{l}\text { U.S. Dept. of } \\
\text { Commerce \& Bur. } \\
\text { of Labor stat. }\end{array}$ & $\begin{array}{l}\text { Argued that IT investments } \\
\text { will help to reverse economic } \\
\text { slowdown in industrial nations }\end{array}$ \\
\hline $\begin{array}{l}\text { PIMS } \\
\text { (1984) }\end{array}$ & $\begin{array}{l}\text { Various } \\
\text { sectors }\end{array}$ & Proprietary & $\begin{array}{l}\text { Strassmann's "return on mgmt," } \\
\text { argued for IT investments as } \\
\text { component of "mgmt capital" }\end{array}$ \\
\hline $\begin{array}{l}\text { Turner } \\
\text { (1985) }\end{array}$ & Banking & $\begin{array}{l}58 \text { mutual } \\
\text { savings banks }\end{array}$ & $\begin{array}{l}\text { No relationship found for org. } \\
\text { perf., and IT expense, usage }\end{array}$ \\
\hline $\begin{array}{l}\text { Bender } \\
(1986)\end{array}$ & Insurance & $\begin{array}{l}132 \text { firms in } \\
\text { Life Office } \\
\text { Mgmt Assn. }\end{array}$ & $\begin{array}{l}\text { Suggested } 15-25 \% \text { of IT } \\
\text { expense/total expense } \\
\text { yields best firm performance }\end{array}$ \\
\hline $\begin{array}{l}\text { Breshnihan } \\
(1986)\end{array}$ & $\begin{array}{l}\text { Financial } \\
\text { services } \\
\text { sector }\end{array}$ & $\begin{array}{l}\text { U.S. Dept. of } \\
\text { Commerce, } 1958 \\
\text { and } 1972\end{array}$ & $\begin{array}{l}\text { Showed that benefits accrue to } \\
\text { customers based on area under } \\
\text { derived demand curve for } \\
\text { mainframe computer services }\end{array}$ \\
\hline $\begin{array}{l}\text { Roach } \\
(1987)\end{array}$ & $\begin{array}{r}\text { Service } \\
\text { sector }\end{array}$ & $\begin{array}{l}\text { U.S. Dept. of } \\
\text { Commerce, } 1950 \mathrm{~s} \\
\text { to } 1980 \mathrm{~s}\end{array}$ & $\begin{array}{l}\text { Suggested IT investments } \\
\text { have done little to improve } \\
\text { productivity in services }\end{array}$ \\
\hline $\begin{array}{l}\text { Banker \& } \\
\text { Kauffman } \\
\text { (1988a) }\end{array}$ & Banking & $\begin{array}{l}508 \text { bank } \\
\text { branches in } \\
\text { Pennsylvania }\end{array}$ & $\begin{array}{l}\text { ATM network membership more } \\
\text { important than branch ATMs to } \\
\text { protect deposit market share }\end{array}$ \\
\hline $\begin{array}{l}\text { Harris \& } \\
\text { Katz (1988) }\end{array}$ & Insurance & $\begin{array}{l}40 \text { firms over } \\
\text { four years }\end{array}$ & $\begin{array}{l}\text { Found that firm profitability } \\
\text { correlated with IT investments }\end{array}$ \\
\hline $\begin{array}{c}\text { Loveman } \\
(1988)\end{array}$ & Manufacturing & $\begin{array}{l}60 \text { bus. units } \\
\text { from 1978-84, } \\
\text { MPIT database }\end{array}$ & $\begin{array}{l}\text { Failed to show a significantly } \\
\text { positive relationship between } \\
\text { IT expense and productivity }\end{array}$ \\
\hline
\end{tabular}

Table 1: Empirical Studies in the IT Business Value Analysis Literature 
Unfortunately, use of the PIMS database and the studies which reported more favorable results for the value of IT expenditures failed to explain how and why IT creates leverage on economic measures of firm and industry performance. The results presented by Bender lack context: knowing that the $20 \%-25 \%$ range for IT as a percentage of total expenditures is correlated with superior performance begs the more difficult question of why these levels make sense in managerial IT investment decisions for a particular organization. In fact, the results of these studies, taken as a group, raise numerous questions about a set of issues that are just coming to be recognized as key dimensions along which methodological advance in IT business value research can proceed. These include:

- Method Selection -- Was the methodology selected well-suited to detecting the mechanisms by which IT business value is created in a department, firm, industry or economy? (Bakos 1987)

- Output Validity -- Were the IT business value measures employed measuring the "right" things? (Kauffman and Kriebel 1988)

- Conversion Effectiveness -- Was the method selected flexible enough to identify contextual factors within the organization which make a difference in converting the IT investment into productive outputs? (Weill and Olson 1989)

- Robust and Refined Results -- What alternative methods might have led to results that were more refined, leaving fewer questions open to debate? (Barua, Kriebel and Mukhopadhayay 1989; and Kauffman, Ghosh and Bansal 1989)

Asking these methodological questions of our own research helped lay a foundation for an evaluative framework which we believe is useful to take a more careful look at each of the IT business value studies.

\section{An Evaluative Framework for IT Business Value Research}

In order to better understand the strengths and limitations of the studies presented above, we introduce a framework consisting of three classes of considerations important for conducting IT business value research.

- Motivation for methods selected, in terms of purpose, methodological approach and theory base;

- Focus of analysis, in terms of unit of analysis, locus or timing of IT value, and the role of information system performance;

- Caveats for measurement, in terms of reliability of specific performance measures, mode of data analysis and importance of organization context.

In the paragraphs which follow, we develop these classes of considerations in some detail, by applying them to each of the IT business value studies as shown in Table 2 below.

\subsection{Motivation for the Methods Chosen}

The questions of methodological approach, purpose and theory base all attempt to get at the basic motivation for each of the IT business value studies we have reviewed. Understanding the motivation behind them is helpful when interpreting the results and determining the, often unstated, paradigm implicit in each study. The motivation and research questions identified within each study also provide insight into the state of IT business value research at the time it was conducted, and how research in this area has progressed since. 


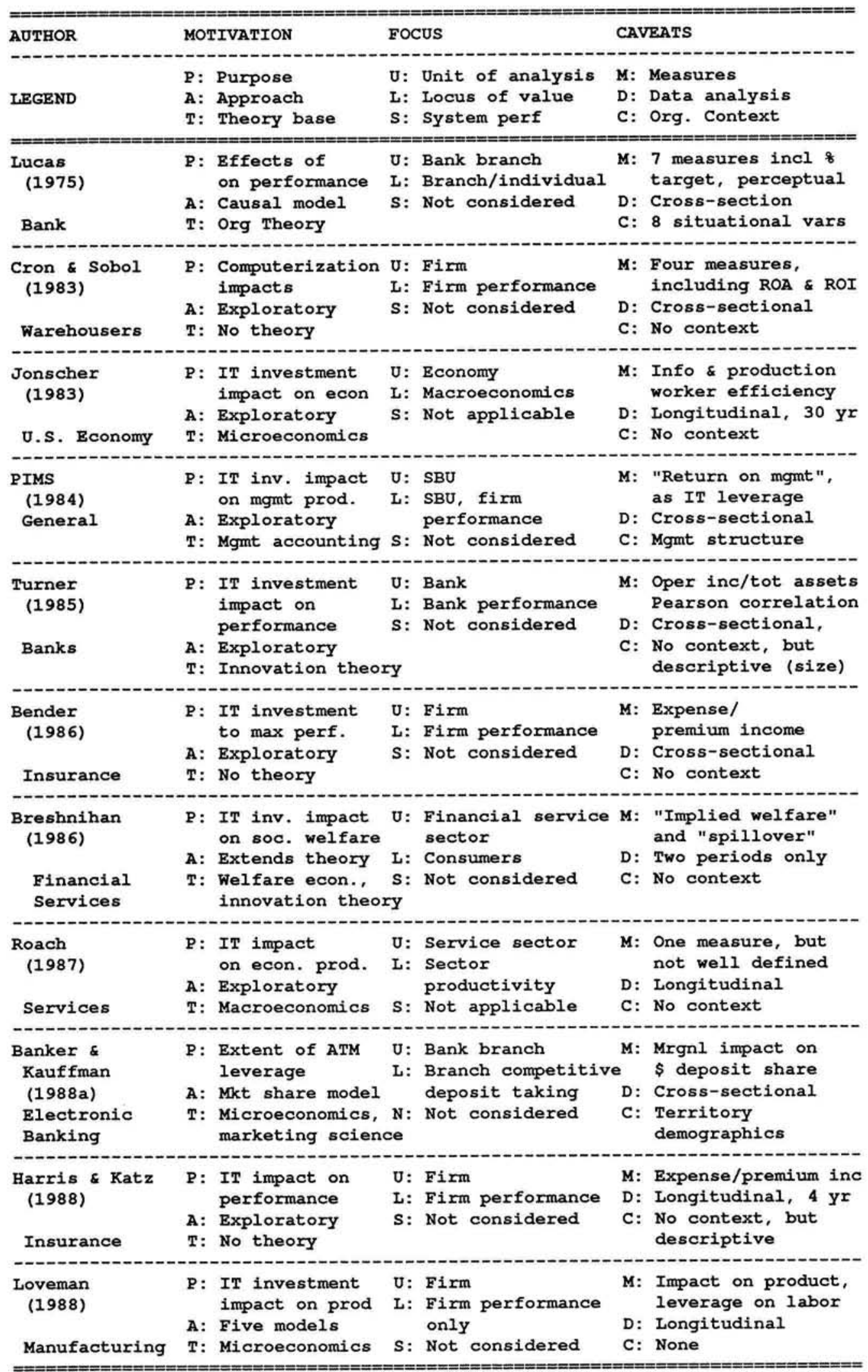

Table 2: Motivation, Focus and Caveats for IT Business Value Studies 


\subsubsection{Purpose}

Purpose (P) identifies the research question(s) addressed in the study. What was the expressed purpose of the study? Is management interested in securing a baseline of performance for an IT investment that has already been made? Or is additional investment being considered that is meant to further leverage existing investment? As the table indicates, the early studies tended to address the question of computer use (Lucas 1975) and the relationship between performance and computerization intensity (Cron and Sobol 1983). These studies used surrogates for IT investment which the later studies measured directly. The studies by PIMS (1984) and Bender (1986) measured the proportion of expenses dedicated to IT in firms, while Breshnihan (1986) and Roach (1987) measured amounts of resources dedicated to IT in a sector.

The difficulty of identifying interesting, consistent results is further compounded by the use of inconsistent definitions of key input and output variables. "IT expenditures" is a good example. Some studies adopted a narrow definition of just information system expenses; others broadened the definition to include communications, software and hardware-related employees, and also managers. ${ }^{2}$ The result for IT business value research, as Bakos has observed, is that little sequential building of understanding has developed. Unlike in other areas where a coherent line of incremental research can be identified, IT business value research has gone through a phase where exploratory studies are driven by diverse base disciplines.

\subsubsection{Methodological Approach}

Methodological approach (A) attempts to capture the essence of the research approach. Was the study testing solid hypotheses coming from a strong theoretical base or was it an exploratory, loosely directed data analysis? The majority (seven) of the studies was classified as exploratory as they were loosely directed data analyses. Exploratory data analysis is useful because it can suggest the kinds of hypotheses to test for IT business value, but this normally requires follow-up research with the same or a supplemented data set.

Four exceptions were identified. Lucas (1975) conducted a test of a causal model driven by a contingency theory approach. Breshnihan (1986), basing his arguments and modeling approach on welfare economics and the theory of innovation, used the notion that the area under the "derived demand curve" for IT (as an intermediate input in financial services) could also be interpreted as a measure of social welfare. Banker and Kauffman (1988a) tested to determine how ATMs indirectly affected bank branch deposit competition via a competitive interaction model of market share. The model they used has been widely validated in the marketing science literature. Loveman (1988), relying on relevant theory from production and labor economics, tested five separate models to determine IT impacts on sectoral production and labor productivity. He was careful to distinguish among models in which output can be tied directly or indirectly to an IT.

When IT can be tied directly to the output, a simplified production function of the form OUTPUT $=f(I N P U T S)$ is an appropriate test. But, when the IT only indirectly affects the production of an output, as in the link between an airline computer reservation system investment and airline profitability, it may be necessary to introduce an intermediate production process. A two-stage model which evaluates two production functions one at a time, e.g.,

\footnotetext{
${ }^{2}$ Weill (1988) contains a review of the range of definitions of IT adopted in the IT business value literature.
} 
INTERMEDIATE OUTPUTS $=\mathrm{f}($ INPUTS $)$ and ECONOMIC OUTPUTS $=\mathrm{g}$ (INTERMEDIATE OUTPUTS $)$, may be more appropriate. Relating this to the airlines example, we might first test to determine whether airline route market shares increase in the presence of concentrated reservation system deployment for that route. The second test would be to determine the extent to which improved market share, among other factors, impacts profitability.

\subsubsection{Theory Base}

A third key aspect of the motivation for the methods used in the studies can be found in their underlying theory base (T). Is there a theory base to suggest hypotheses to test? Can the analyst rely on strong results from a large body of literature related to the theory base? Each theory base brings with it different methodologies, assumptions and value systems. The most commonly represented theory base was economics. The studies by Jonscher (1983), Breshnihan (1986), Banker and Kauffman (1988a), and Loveman (1988) all used microeconomic theory to frame their IT business value models. Microeconomic theory offers a strong and insightful theory base, which enables the creation of flexible analytic and testable empirical models. The breadth of potential coverage for IT business value models based on economic concepts is broad, but models leading to powerful tests in one environment, or for one level of analysis, may not be easily transferred to other environments or levels of analysis.

Most of the studies inspired by economics generally have not included organization context, rather concentrating on broader firm, industry and economy trends. The studies by Jonscher (1983) and Roach (1987) were exploratory in nature. On the other hand, several had no identifiable theory base and were pure data exploration (Cron and Sobol 1983; Harris and Katz 1988; and Bender 1986). The remainder relied on organization theory (Lucas 1975a), management accounting (PIMS 1984), and innovation theory (Turner 1985), respectively.

\subsection{Focus of Analysis}

The unit of analysis, locus of value and the role of information system performance all describe the focus of an IT business value study. The focus includes what aspect of performance is of greatest interest to the researcher, what unit of the business under investigation and whether the systems information systems are directly considered.

\subsubsection{Unit of Analysis}

The unit of analysis (U) of the study indicates the level at which various techniques are applied to the relevant data to identify IT business value (e.g., the five levels discussed by Bakos). The unit of analysis is often suggested by the theory base used in the study. For each unit of analysis adopted an implicit assumption is made: that a relationship is present between the IT investment and value created at that level. In order to find a relationship between IT investment and performance the link between investment and performance must be bounded by the unit of analysis. In addition, the higher the level of aggregation, the greater the chances are of diluting the evidence that a link does exist.

Five of the studies used the firm as the unit of analysis (Cron and Sobol 1983; Harris and Katz 1988; Turner 1985; Bender 1986; and Loveman 1988). This unit of analysis suffers from potential dilution when a firm has several radically different business units. This highlights the idea that intermediate production is occurring which cannot be adequately expressed in a model which captures secondary impacts of IT at the firm level. Three of the studies 
addressed this problem and used a firm subunit as the unit of analysis, e.g., the strategic business unit (SBU) or bank branch (PIMS 1984; Lucas 1975; and Banker and Kauffman 1988a). The remaining studies looked at the sectoral and social value of IT, using the financial services sector, and the economy as a whole as the separate units of analysis (Jonscher 1983; Breshnihan 1986; and Roach 1987). This unit of analysis maximizes the likelihood of dilution and allows the effects of many unidentified mediating and moderating variables to go unnoticed. Failure to recognize the importance of the potential dilution can easily invalidate the results of an IT business value analysis.

\subsubsection{Locus and Timing of IT Value}

Identification of the timing of IT value $(\mathbf{L})$ is crucial. Investments in IT will take time to add value to a firm and show up in performance measures. This time lag is often omitted from models and not considered in most crosssectional studies. Organizations absorb technology at different rates and omitting the possibility of a time lagged effect is a potentially serious shortcoming of an IT business value study.

In addition, as is often the case in exploratory research, most attempts to accurately measure when value accrues after an IT investment has been made have not been well-grounded in theory. For example, Loveman (1988) tested models for IT business value with and without lagged independent variables. Although the forms of the models he tested make intuitive sense, they are subject to the criticism that no adequate theory was employed to determine which variables should have been lagged and what the lags were. Lucas (1975) summed up another problem associated with using lagged variables: "Because of the time lags among the variables, a priori reasoning on the direction of causality is often difficult." Weill's (1988) recent results on valve manufacturers' IT investments supported Lucas' view. An important goal of Weill's study was to identify whether levels of IT investment in previous periods correlated with improved firm performance, but he also found that good performance in previous periods correlated with IT investments in later periods. This clouded the distinction between performance, which has traditionally been viewed as a dependent variable, and IT investment as an independent variable: their relationship may be circular.

The locus of IT value (L) addresses the kinds of IT business value measured. IT could potentially create value at many levels and in each study the researchers have defined a target locus of value. At first glance, it may seem as though the unit of analysis is functionally defined by the locus of value. For example, if the locus of value is firm performance then one might expect the unit of analysis to be the firm. Yet in several studies there was more than one locus, e.g., both bank branch and individual (Lucas 1975), and SBU and firm (PIMS 1984). In the remaining studies, the locus of value was broader, e.g., sector productivity (Jonscher 1983; and Breshnihan 1986).

The locus of value need not explicitly determine the unit of analysis, however. The studies by Breshnihan (1986), and Banker and Kauffman (1988a) are useful illustrations of this idea. Breshnihan's locus of value was aggregate consumer welfare. But he did not measure IT business value at this locus directly; data simply were not available. Instead, he made concessions to the difficulties of data collection, and devised a means to avoid the problem altogether, by shifting the unit of analysis to firm demand for mainframe computer services. Banker and Kauffman recognized that most previous work on ATM value looked at aggregate impacts on firm performance, and dilution has resulted in weak and uncertain results. But, by shifting the unit of analysis to bank branch deposit competition, 
the authors were able to show how ATMs leveraged a well-defined component of bottom line performance. ${ }^{3}$

\subsubsection{The Role of Information System Performance}

Much of the early research on information systems impact on organizations considers the role of the performance of the specific information system(s) or technology (S) under study. Some studies imputed information system performance using measures of user satisfaction (Ives, Olson and Baroudi 1983), system success (Martin 1982), system effectiveness (Srinivasan 1985) or system quality (Ginzberg 1979). None of the studies considered information system performance explicitly. Instead, the implicit assumption was made that IT investment (or use) influences organizational (or sector) performance. The intervening variable of information system performance was ignored, even though it is certain that given similar investments in different firms or divisions, there will be variability in information system performance and use. This variability is bound to affect the potential business value to be gained from IT investment. However, based on what we have learned from the recent studies on electronic banking (Banker and Kauffman 1988a) and treasury management workstations (Kauffman and Kriebel 1989), it is clear that system performance in isolation is rarely a good way to measure business value. In methodological terms, system performance is a mediating, not criterion, variable.

\subsection{Other Caveats for Measurement}

The final dimension of our evaluative framework for conducting studies to assess IT business value is the measurement caveats which should be considered. These include the reliability of performance measures, mode of data analysis, and importance of organization context.

\subsubsection{Reliability of Specific Performance Measures}

Once a theory base and methodology have been chosen, and the unit of analysis has been decided upon to measure IT impact at its locus of value, the next logical step in the progression is to select a set of performance measures. Kauffman and Kriebel (1989) have argued that it is rare that "unitary measures" will suffice; instead, measurement of IT business value is best thought of as a process of triangulating to identify the presence first and then the magnitude of the value created. In some cases, it is sufficient to construct very rough measures which act as "ballpark" estimators for value; this depends on the kinds of questions management wishes to have answered. In other cases it is crucial to construct very sensitive measures to provide evidence that a hypothesized impact is actually occurring.

Banker and Kauffman (1988b) have argued that measures (and models to identify the "business value linkage") should be constructed with the locus of value in mind. For example, if an airline IS executive believes that computer reservation systems helped to gain market share, then this assertion would have to be tested in the context of a model for airline market share. If ATMs are thought to lead to cost reductions in the bank branch, then models should be constructed which estimate both the direct and indirect impacts on branch teller labor and funding costs (Banker and

\footnotetext{
${ }^{3}$ Another study is in progress which recognizes this distinction. Barua, Kriebel and Mukhopadhayay plan to look at relative performance among firms in the MPIT database by employing "path analysis" to explain firm level performance through intermediate production activities, such as inventory management. An overview of the research they are carrying out is found in Barua, Kriebel and Mukhopadhayay (1989).
} 
Kauffman 1988c). Finally, Banker, Kauffman and Morey (1989) have suggested that IT business value measures must represent the probabilistic nature of IT impacts. In fast food operations, for example, IT is often deployed to reduce resource waste and improve coordination, but there may be other factors in the environment (e.g., management control procedures, peak demand characteristics and varying levels of trained staff) that either increase or decrease the likelihood that IT will have the intended effects.

The authors of the studies we reviewed evidenced little agreement on what the "right" measures of IT business value were. At the firm and industry levels of analysis, ROA and ROI were natural choices -- they are monitored by senior management and were readily available. But these are aggregate measures in which the value of IT is likely to be diluted, if it is present at all. The studies by Breshnihan (1986) and Banker and Kauffman (1988a) (and Loveman (1988) to a lesser extent) incorporated the kinds of measures that are most likely to lead to methodological progress. Each study derived measures directly related to the theory bases used (derived demand for mainframe services as a measure of consumer welfare, marginal branch deposit market share, and manufacturing firm output quantity).

\subsubsection{Mode of Data Analysis}

The mode of data analysis (D) refers to whether the research uses cross-sectional or longitudinal data to establish value estimates for IT investments. The choice of cross-sectional or longitudinal data for an IT evaluation is crucial, and each of the studies which chose the sector or economy locus of value used longitudinal data (Jonscher 1983; Breshnihan 1986; Roach 1987; and Loveman 1988). Since Breshnihan was focusing on the cumulative change in consumer welfare between the 1950 s and the 1970 s, he only required data for two representative years. Where a continuous time-series is needed, the analyst must take special care to ensure the data obtained are actually measuring the same things at different points in time. As an example, consider the value of computer reservation systems in terms of commercial airlines' financial performance. It would be very difficult to measure at the firm level using longitudinal data; the industry has undergone significant consolidation due to changes in its regulatory environment. Testing for reservation system value would pose difficult problems for the best econometrician.

Six of the studies used cross-sectional analysis. Cross-sectional analysis is often more attractive due to data availability. Some of the standard sources area include government organizations, industry and trade associations, and firms which specialize in analyzing certain industries. For example, Turner (1985) obtained data from the National Association of Mutual Savings Banks, while both Bender (1986) and Harris and Katz (1988) obtained data from the Life Office Management Association. Banker and Kauffman (1988a) used a combination of the three strategies, obtaining U.S. census data from a market research firm, data on deposit market share from a compilation of regulatory reports for individual banks, and ATM location data from the publications of a shared ATM network.

Cross-sectional data alone can provide interesting insights into relative investment and performance. In addition, when longitudinal data are difficult to collect, it is possible to use cross-sectional data to simulate a time-series. This is done by ensuring that there are firms in the data set that have or have not invested in a specific IT, and then testing whether a specific impact occurs in both cases. (See, for example, Banker, Kauffman and Morey (1989).) A time-series of cross-sections would be the ideal data set. Banker and Johnston (1989), in a recent study of computerized reservation system impacts on airline market shares, completed one of the only studies in the IT business value literature which has utilized panel data and the powerful techniques available to analyze it. 


\subsubsection{Importance of Organization Context}

Bakos (1987) asserted that answering questions about the value of IT places a premium on identifying "methodologies [that] allow us to control or compensate for contextual variables when it is feasible." Organization context (C) is an important concern that the IT business value literature as a whole has almost entirely failed to address. It refers to the characteristics of the organization that tend to influence the relationship between IT investment and firm performance. This context is specific to each organization and enriches the data used in the analysis. Contextual factors can be any characteristic of an organization that theory indicates will moderate the relationship between IT investment and performance, and thus, predict how effective a firm is in converting an IT investment into business value. Weill (1988) identified four organization context variables that made up conversion effectiveness: top management commitment to the IT; organization experience with the IT; satisfaction with the IT; and the extent of political turbulence within the organization. He found that conversion effectiveness moderated the relationship between IT investment and firm performance in the valve manufacturing sector.

Among the studies we cited, Lucas (1975) most fully deals with the problem of organization context. He incorporated eight variables to describe bank branch operating environments, including such concerns as the potential business levels of a location, the stability of its customer base, whether it was a hub office, and the intensity of competition nearby. Suggesting the measurement difficulties involved, Lucas found "little apparent consistency in the nature of the relationship[s]" among his performance measures and these situational variables. A second set of contextual factors included in his study involved the decision styles and other personal descriptors for managers which were believed to have an effect on system usage and managerial action. Lucas' analysis is useful because it points out the variety of contextual factors that can potentially influence conversion effectiveness. Banker and Kauffman (1988a) also included a consideration of context. Based on the results of their field study, they distinguished between the contexts of savings and demand deposit market share competition. Finally, since the leverage that ATM deployment creates on branch market shares was estimated for bank branches in separate territories, a description of the intensity of competition was implicit in the market share models used.

Recognition of the organization context suggests that extreme care must be taken to incorporate into the analysis information that managers have about a given IT investment evaluation problem. This makes the analysis more relevant from a manager's perspective: the more information the value measure takes into account, the more likely they are to explain individual firm variance.

Barua, Kriebel and Mukhopadhayay (1989) suggested another way this problem can be addressed: by partitioning the data sets employed in the value analysis. Partitioning a data set is analogous to using categorical variables which describe the partitions, and then running a value analysis on pooled data. The authors pointed out that "bimodality" -- when high IT expenditures are observed to lead to both high and low firm revenues or return on investment in different firms -- is symptomatic that the wrong unit of analysis has been chosen, or that other contextual factors need to be better represented. Among the studies we reviewed, the results of Cron and Sobol (1983), Harris and Katz (1988), Bender (1986) and Loveman (1988) are subject to this criticism. Banker and Kauffman (1988a), however, employed data set partitioning, to control for deposit competition taking place in territories where different ATM networks dominated. They found that this led to more refined estimates of ATM business value. 


\subsection{Two Recent Studies}

To complete our review of IT business value studies we next discuss some of our own recent work. When we commenced our research we benefitted from the base of experience created by the previous studies. This also encouraged us to identify new and potentially useful approaches. Our two studies were in different sectors -electronic banking (Kauffman, Ghosh and Bansal 1989) and valve manufacturing (Weill 1988) -- and used very different methodologies. The electronic banking study made use of recent developments in equilibrium models for market share estimation from marketing science. The valve manufacturing study took a behavioral view using contingency theory. Table 3 below presents our studies using the evaluative framework.

Kauffman, Ghosh and Bansal (1989) offered a new approach to IT business value research, particularly in the area of methodology. First, they suggested a means to refine IT business value estimates using "jackknife statistics." Their goal was to determine if the local contexts of ATM deployment tended to enhance or suppress business value. Jackknife statistics provide a means to determine the extent to which subsets of observations in a data set leverage the parameter estimates for a model which includes all observations. Second, using the same unit of analysis throughout (the bank branch) and careful data partitioning, the evaluation was able to focus on key issues of interest to management. Third, this kind of analysis also opens up the possibility of testing to determine whether the jackknife statistics systematically vary with aspects of the demographic and competitive environment not explicitly included in a market share model. This provides useful information for management about the kinds of information which should be tracked in a database for the performance of retail banking technologies.

Weill (1988) used hierarchical regression to study a sample of valve manufacturing firms using six years of data. This historical data allowed the firm's current performance, with the effects of previous performance statistically removed, to be regressed against IT investment. This method significantly increased the explained variance and statistical power of the models. Another aspect of this work was the recognition that all IT investments were not alike. The performance effects of three different kinds of IT investments (strategic, informational and transactional) were studied. Finally, Weill's use of contextual variables (e.g., internal firm political turbulence and IT experience) attempted to capture individual firm differences. These differences related to how successful different firms were in converting their IT investments into productive outputs.

\section{Conclusions}

\subsection{Recommendations for Improving IT Business Value Research}

A number of recommendations emerged from the use of our evaluative framework and our own efforts to study IT business value. The types of data required for this work are very difficult to obtain. Firms are often reluctant to divulge IT investment and performance information. Worse still, many firms may not track their firm-wide IT investments, only thinking in terms of DP department budgets. In addition, it may not be sufficient to track the investment side alone. Since many of the impacts that IT creates are "ripple effects" in areas of a firm outside the DP department, care must be taken to track measures relevant to them. For these reasons it is important that a large data gathering effort be preceded by a strong research design that has benefitted from the joys and frustrations of previous work. 


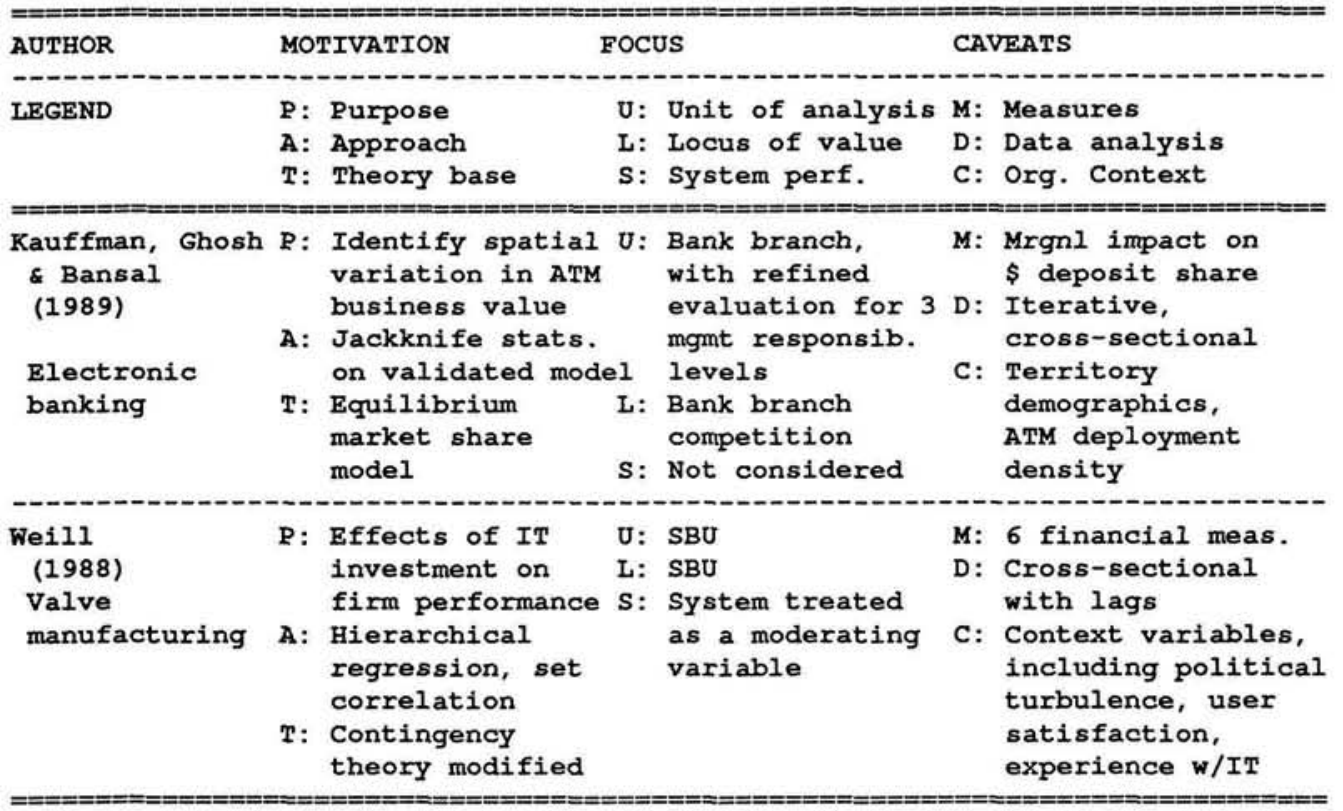

Table 3: Motivation, Focus and Caveats for Illustrations 
Recommendation \#1: Concentrate on Theory Building and Refinement

In our view IT value research is still in its adolescence. A sufficient amount is not yet known about the process of how and why IT investment influences firm performance to make IT investment evaluation a straightforward task for managers. As a result, it is probably premature for researchers to launch completely into theory testing. Instead, we suggest that researchers continue to concentrate their efforts on theory building approaches that hold out the promise of generalizing the results and the methods across various technologies and IT deployment situations.

\section{Recommendation \#2: Conduct Purposeful, Model-Instantiating Survey Research}

Commenting on the state of "survey research" in IS, Lucas (1989, p. 16) recently observed that researchers "continue to publish papers ... with no research model, no hypotheses or theory, and which present their results in the form of frequency distributions and descriptive statistics." We advocate survey approaches for IT business value research provided they are carried out to instantiate well-defined models, that are carefully thought out in advance of the time data collection begins. We also concur with Lucas that advances in IT business value research will result from "well-defined studies of hard problems," even though they may produce only "modest results."

\section{Recommendation \#3: Collect Historical or Longitudinal Data}

Cross-sectional data provides a snapshot at one point in time. But the process through which IT affects performance takes time. This contradiction suggests that collecting data over time is an important ingredient for IT value research. This is particularly true if the researcher is interested in teasing out two potential effects: the influence of IT investments on the firm's performance, and the influence of the firm's performance on what they will and can invest in IT.

\section{Recommendation \#4: Adopt Consistent Definitions and Value Measures of IT}

One of the difficulties of comparing research on firm-level impacts of IT is that the definitions for IT which are used are often inconsistent. Some studies included just DP departments; others used firm-wide IT. At this level of analysis, we suggest that a broad definition be adopted including all firm-wide IT and aspects of IT, for example, including communications. At lower levels of analysis this is less important, but care should still be given to basing definitions of IT, where possible, on workable constructs from prior research. A similar argument holds for choosing IT value measures. Where possible, researchers should attempt to extend and refine measures from prior research, for use in new measurement situations.

\section{Recommendation \#5: Recognize the Need for Stochastic Models of IT Business Value}

Since IT is often just one of a number of factors influencing economic measures of firm performance, IT business value models should take care to represent the other factors, as well as IT. Even when IT-related variables are included, however, there still is a strong likelihood that IT will not have the same effect in all the areas of the firm it is meant to benefit. Sometimes management policies, competitive circumstances, and characteristics of the firm's operations or customer base do not provide homogenous environments in which value from IT investment can be realized. Researchers have two basic ways to proceed: 
- attempt to identify a priori a "long list" of moderating variables and incorporate those into the IT valuation model;

- work with a more "naive" model which initially replaces the moderating variables with a "stochastic component", and then attempt to understand how and why it varies.

We advocate the latter strategy. It structures the process in which a researcher develops business value estimates. Initial estimates can be obtained which will prompt management to ask more refined questions about the ways in which IT creates value. Then the initial estimates can be refined, for example, by devising tests to explain the stochastic component in the valuation model. This process will provide more information that will help managers improve their control and future investment decisions.

\section{Recommendation \#6: Use the Evaluative Framework as a Guide}

We found the evaluative framework very useful in assessing our own IT value work. The three classes of considerations -- Motivation for Methods Selected, Focus of Analysis, and Caveats for Measurement -- provide a checklist of important questions. Within each class several general headings need to be addressed. For example, when considering Caveats to Measurement the first general heading is performance measures. Are the performance measures convincing, reliable and obtainable? Are they the measures managers wish to affect with their investments in IT? Since the effect of IT on many measures of firm performance is diluted by the influence of other factors, and thus the choice of appropriate measures becomes vital. Many of the questions our framework raises need to be brought up before the researcher commits to a business value modelling approach or the manager implements a data collection strategy.

\subsection{Some Final Thoughts on New Theory Bases for IT Business Value Research}

Since the use of strong theory bases will improve the likelihood of achieving meaningful IT impact analysis results, future IS research should tap a broad range of applicable theories and methods. For example, Kriebel (1989) argued that management science methods could be used to focus on IT's role to promote "frontier efficiency" and improve managerial decisions; Bakos (1987) suggested industrial economics and organizational theory; Crowston and Treacy (1986) recommended transaction cost theory and marketing channels, among others. and Kauffman, Ghosh and Bansal (1989) recently pointed out that marketing science offers a rich body of methods for IT business value research.

Moreover, it appears that many other new areas also should be explored -- including behavioral decision theory from psychology, project management and scheduling theory from operations management, location theory from operations research, agency theory from accounting and finance, game theory from microeconomics, and modern macroeconomic theory -- just to name a few. All these areas offer IT business value researchers rich new means by which methodological progress can be achieved.

This paper has been the result of the synthesis of two quite different approaches to IT investment analysis: economics and behavioral science. The framework we presented suggests the common ground we have found, and 
the potential we see for continued advances in the field of IT business value research. ${ }^{4}$

\footnotetext{
${ }^{4}$ The authors wish to thank Sirkka Jarvenpaa, Charles Kriebel, Hank Lucas and two anonymous referees for their helpful discussions and comments on prior drafts of this paper. Additional thanks go to participants in the Information Systems doctoral rolling readings seminar at NYU, who reviewed many of the papers we discussed and helped us to sharpen our critique.
} 


\section{References}

[1] Bakos, J. Y.

Dependent Variables for the Study of Firm and Industry-Level Impacts of Information Technology.

In Proceedings of the Eighth International Conference on Information Systems. Pittsburgh, Pennsylvania, December, 1987.

[2] Banker, R. D., and Kauffman, R. J.

Strategic Contributions of Information Technology: An Empirical Study of ATM Networks.

In Proceedings of the Ninth International Conference on Information Systems. Minneapolis, Minnesota, December, 1988a.

[3] Banker, R. D., and Kauffman, R. J.

A Scientific Approach to the Measurement of IT Business Value -- Part I: A Manager's Guide to 'Business Value Linkage' Impact Analysis.

September, 1988b.

Working Paper \#194, Center for Research on Information Systems, Stern School of Business, New York University.

[4] Banker, R. D., and Kauffman, R. J.

A Scientific Approach to the Measurement of IT Business Value -- Part II: A Case Study of Electronic Banking Operations at Meridian Bancorp.

September, 1988c.

Working Paper \#195, Center for Research on Information Systems, Stern School of Business, New York University.

[5] Banker, R. D.; Kauffman, R. J.; and Morey, R. C.

Measuring Input Productivity Gains from Information Technology.

January, 1989.

Working Paper \#196, Center for Research on Information Systems, Stern School of Business, New York University.

[6] Banker, R. D., and Johnston, H.

Complementarity and Substitution in the Use of IT: A Study of the Airlines' Computerized Reservation Systems.

1989.

Working Paper, School of Urban and Public Affairs, Carnegie Mellon University.

[7] Barua, A.; Kriebel, C. H.; and Mukhophadhayay, T.

A New Approach to Measuring the Business Value of Information Technologies.

January, 1989.

Working Paper, Graduate School of Industrial Administration, Carnegie Mellon University.

[8] Bender, D. H.,

Financial Impact of Information Processing.

Journal of Management Information Systems 3(2), Fall, 1986.

[9] Berger, P., J. G. Kobelius and D. E. Sutherland (editors).

Measuring Business Value of Information Technologies.

ICIT Press, Washington, D.C., 1988.

[10] Breshnihan, T. F.

Measuring the Spillovers from Technical Advance: Mainframe Computers in Financial Services. American Economic Review 76(4):742-755, September, 1986.

[11] Computerworld.

Editorial -- The Perception.

Computerworld, December 5, 1988.

[12] Computerworld.

The Premier 100 -- The Companies Investing Most Effectively in Information Systems.

A Supplement to Computerworld, June 20, 1988. 
[13] Connolly, J.

Study: Spending Up; Stress on Strategy.

Computerworld, November 28, 1988.

[14] Cron, W.; and Sobol, M.

The Relationship between Computerization and Performance: A Strategy for Maximizing Economic Benefits of Computerization.

Information And Management 6:171-181, 1983.

[15] Crowston, K., and Treacy, M. E.

Assessing the Impact of Information Technology on Enterprise Level Performance.

In Proceedings of the Seventh International Conference on Information System, pages 299-310. San Diego,

CA, December, 1986.

[16] Ginzberg, M. A.

A Study of the Implementation Process.

TIMS Studies in Management Science 13:85-102, 1979.

[17] Harris, S. E., and Katz, J. L.

Profitability and Information Technology Capital Intensity in the Insurance Industry.

In Proceedings of the Twenty-First Annual Hawaii International Conference on System Sciences, pages

124-130. January, 1988.

[18] Ives B.; Olson, M. H.; and Baroudi, J. J.

An Empirical Study of the Impact of User Involvement on System Usage and Information Systems.

Communications of the ACM 29(3):232-238, March, 1983.

[19] Jonscher, C.

Information Resources and Economic Productivity.

Information Economics and Policy 1: 13-35, 1983.

[20] Kauffman, R. J.

Assessing the Performance of Information Technologies Which Deliver Financial Services.

$\mathrm{PhD}$ thesis, Graduate School of Industrial Administration, Carnegie Mellon University, 1988.

[21] Kauffman, R. J.; Ghosh, A.; and Bansal, A.

Parameter Non-Stationarity in a Model Which Estimates the Business Value of Information Technology.

January, 1989.

Working Paper \#197, Center for Research on Information Systems, New York University.

[22] Kauffman, R. J., and Kriebel, C. H.

Modeling and Measuring the Business Value of Information Technology.

In Berger, P.; Kobelius, J.; and Sutherland, D. E. (editors), Measuring the Business Value of Information Technologies. ICIT Press, Washington, D.C., 1988.

[23] Kauffman, R. J., and Kriebel, C. H.

Identifying Business Value Linkages for Production Processes Involving Information Technology.

In Y. H. Kim and V. Srinavasan (editors), Advances in Working Capital Management: Volume II. JAI Press, New Haven, CT, 1989.

Forthcoming.

[24] Kriebel, C. H.

Understanding the Strategic Investment in Information Technology.

In K. C. Laudon, and J. Turner (editors), Information Technology and Management Strategy, pages 106-118. Prentice-Hall, Englewood Cliffs, NJ, 1989.

[25] Loveman, G.

An Assessment of the Productivity Impact of Information Technologies.

1988.

Working paper, Management in the 1990s, Sloan School, MIT. 
[26] Lucas, H. C., Jr.

The Use of an Accounting Information System, Action and Organizational Performance.

The Accounting Review :735-746, October, 1975.

[27] Lucas, H. C., Jr.

Methodological Issues in Information Systems Survey Research.

1989.

Working Paper \#206, Center for Research on Information Systems, Stern School of Business, New York University.

[28] Martin, E. W.

Critical Success Factors of Chief MIS/DP Executives.

MIS Quarterly 6(2), June, 1982.

[29] The PIMS Program.

Management Productivity and Information Technology.

The Strategic Planning Institute, Cambridge, MA., 1984.

[30] Roach, S. S.

Technology and the Service Sector: America's Hidden Competitive Challenge.

Economic Perspectives -- Morgan Stanley, August, 1987.

[31] Srinivasan, A.

Alternative Measures of System Effectiveness: Associations and Implications.

MIS Quarterly 9(3):243-253, September, 1985.

[32] Turner, J.

Organizational Performance, Size and The Use of Data Processing Resources.

1985.

Working Paper \#58, Center for Research in Information Systems, New York University.

[33] Weill, P.

The Relationship Between Investment in Information Technology and Firm Performance in the Manufacturing Sector.

$\mathrm{PhD}$ thesis, Stern School of Business, New York University, 1988.

[34] Weill, P., and Olson, M. H.

Managing Investment in Information Technology: Mini-Case Examples and Implications.

MIS Quarterly, March, 1989.

[35] Zimmerman, W., ed.

American Banker 1988 Managing Technology Survey: The Impact on the Bottom Line. International Thompson Publishing Corp., New York, NY, 1988. 